\title{
A Support Group for Patients Who Have Recovered From Thrombotic Thrombocytopenic Purpura-Hemolytic Uremic Syndrome (TTP-HUS): The Six-Year Experience of the Oklahoma TTP-HUS Study Group
}

\author{
Mark A. Howard, ${ }^{1}$ Deanna Duvall, ${ }^{3}$ Deirdra R. Terrell, ${ }^{1,2}$ Anne T. Christopher, ${ }^{4}$ Ira Thomas, ${ }^{1}$ \\ Natalie Holloway, ${ }^{1}$ Sara K. Vesely, ${ }^{1,2}$ and James N. George ${ }^{1,2 *}$ \\ ${ }^{1}$ Hematology-Oncology Section, Department of Medicine, College of Medicine, \\ The University of Oklahoma Health Sciences Center, Oklahoma City \\ ${ }^{2}$ Department of Biostatistics and Epidemiology, College of Public Health, The University of Oklahoma \\ Health Sciences Center, Oklahoma City \\ ${ }^{3}$ The Oklahoma Blood Institute, Oklahoma City \\ ${ }^{4}$ Pain Evaluation and Treatment Center, Tulsa, Oklahoma
}

\begin{abstract}
A support group for patients who have recovered from thrombotic thrombocytopenic purpura-hemolytic uremic syndrome (TTP-HUS), named The Oklahoma TTP-HUS Study Group, has been a successful program for 6 years. This group has met 3 times each year with an average attendance of 16 former patients; in addition, an average of 14 family members and friends have attended each meeting. Eighty-four percent of patients who attended a meeting were women as compared to $68 \%$ women among those who did not attend $(P=0.016)$. Twenty-three percent of patients who attended a meeting have relapsed as compared to $8 \%$ among those who did not attend $(P=0.006)$. There was also a difference in the rates of attendance among the different clinical categories of patients $(P<0.001)$. A survey of former patients, as well as their families and friends, documented that interest in learning more about TTP-HUS and talking with other people who have had TTP-HUS were principal motivations for attending the meetings. The meetings of The Oklahoma TTP-HUS Study Group have been successful not only for support of former patients but also for research. Long-term patient follow-up has been facilitated and the group discussions have revealed previously unreported persistent problems with cognitive ability and endurance. A survey of member centers of the American Association of Blood Banks and America's Blood Centers revealed no similar programs for patients who have recovered from TTP-HUS. The absence of a support group for TTP-HUS in the national survey contrasts to the 274 patient support groups and related wellness/education classes, including some for rare disorders, currently active in the Oklahoma City metropolitan area. The experience of The Oklahoma TTPHUS Study Group suggests that it serves a previously unmet need. J. Clin. Apheresis 18:16-20, 2003.

(c) 2003 Wiley-Liss, Inc.
\end{abstract}

Key words: thrombotic thrombocytopenic purpura (TTP); hemolytic-uremic syndrome (HUS); support group

\section{INTRODUCTION}

Support groups are common, typically established to help people cope with current and continuing problems. A support group for people who have recovered from thrombotic thrombocytopenic purpura-hemolytic uremic syndrome (TTP-HUS) is not consistent with this traditional concept, since they have no apparent current or continuing illness. It is commonly assumed that after recovery from an acute episode of TTP-HUS, there is no need for continuing support.

Seven years ago, a patient who had recovered from TTP-HUS and who had experience in counseling, asked us about organizing a support group. We were initially reluctant, because the potential benefits were uncertain while the risks seemed substantial. TTP-
HUS is a syndrome causing critical illness, but the diagnostic criteria are not specific and the clinical presentations are diverse [1,2]. We anticipated that the different experiences of these former patients would make it difficult for them to relate to one another. We were concerned that for former patients to hear multiple descriptions of unfamiliar critical

*Correspondence to: James N. George, M.D., The University of Oklahoma Health Sciences Center, Hematology-Oncology Section, P.O. Box 26901, Oklahoma City, OK 73190.

E-mail: Jim-George@OUHSC.edu

Received 20 September 2002; Accepted 21 October 2002

Published online in Wiley InterScience

(www.interscience.wiley.com)

DOI: $10.1002 /$ jca. 10045 
complications would increase apprehension rather than provide comfort and reassurance.

However, with persistent encouragement from former patients, we had our initial meeting in October 1996. Over the past 6 years, we have had three meetings each year, each well attended and each with enthusiastic endorsement of this program. Because of sensitivity about identifying former patients as "patients," and because the term "support" did not seem to completely describe our goals, the group decided on the name "Study Group," as commonly used in community and church activities. The group also adopted these goals: "To provide information about TTP-HUS to former patients and their families. To learn new information from our experiences." These goals emphasize that the former patients attend these meetings not only to learn more about TTP-HUS, but also to teach our physicians and staff from their own experiences. This report describes the structure, function, and outcomes of The Oklahoma TTP-HUS Study Group.

\section{METHODS}

\section{The Oklahoma TTP-HUS Registry}

The Registry includes all patients referred to the Oklahoma Blood Institute (OBI) for plasma exchange treatment for clinically suspected TTP or HUS [2]. Since the OBI is the sole provider of plasma exchange services for central-western Oklahoma, we can identify an inception cohort of all patients in whom the diagnosis of TTP-HUS was suspected and a decision to initiate plasma exchange treatment was made. Our practice is to treat all adult patients who may be considered to have either TTP or HUS with plasma exchange. Therefore, all patients with either syndrome are enrolled in The Oklahoma TTP-HUS Registry. We have identified and followed prospectively 280 consecutive patients who had their first episode of clinically suspected TTP-HUS from January 1, 1989 to the present time, August 28, 2002. One hundred and seventy patients survived for more than 30 days following completion of plasma exchange treatment and were alive in 1996; attendance at a Study Group meeting was theoretically possible for these patients. The Registry is approved annually by the institutional review boards of the University of Oklahoma Health Sciences Center and all participating hospitals.

\section{Facilities and Personnel}

Meetings, with supper provided, are held 3 times each year at the OBI from 6:00-8:30 p.m. The OBI is a central location and familiar organization, since plasma exchange was the common treatment for all patients. Meetings are organized by Deanna Duvall, RN, Manager of OBI Therapeutic Services. Each program has been led by James N. George, MD, the physician principally involved in the acute care and follow-up of all patients.

\section{Questionnaires for Patients, Their Families, and Friends}

In July 2002, questionnaires, with a stamped selfaddressed envelope, were mailed to 129 currently surviving patients. The 41 patients who have died since 1996 are principally patients who also had another severe disease, who survived for more than 30 days after completing plasma exchange treatment but then died of their primary disease. Separate questionnaires were created for: (1) patients who had attended one meeting, (2) patients who had attended more than one meeting, (3) families and friends of patients who had attended a meeting, and (4) patients who had not attended a meeting. The questionnaires asked for responses concerning reasons for attending or not attending the meetings, value of the meetings, and suggestions for future meetings. There was no linkage of questionnaires to the former patients' identity.

\section{Survey of Blood Centers}

All 96 members of the American Association of Blood Banks (AABB) were asked to respond to a onequestion questionnaire about knowledge of any TTPHUS patient support programs. The request for information was included in the July 12 issue of the online $A A B B$ Weekly Report, which is accessible to all AABB institutional members as well as to individual subscribers. The same one-question questionnaire was also sent to the 75 blood centers who are also members of America's Blood Centers (ABC) by an e-mail list-serve.

\section{Survey of Oklahoma City Support Groups}

Lists of support groups and related wellness/education classes in the Oklahoma City metropolitan area were obtained from (1) the Web site www. NewsOK.com, produced by The Daily Oklahoman newspaper and television channel 9 and sponsored by the Oklahoma Health Center, (2) the Oklahoma County Medical Society, and (3) the Oklahoma City chapter of the American Cancer Society.

\section{RESULTS}

Figure 1 illustrates the number of patients who have attended each of the 18 meetings. For the 18 


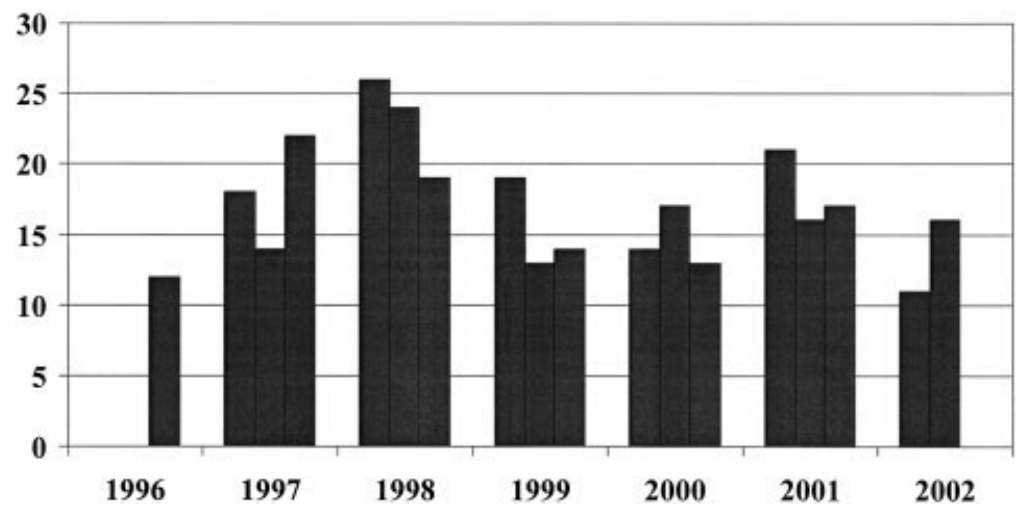

Fig. 1. Attendance of former patients at each of the 18 meetings of The Oklahoma TTP-HUS Study Group, 1996-2002. Meetings are held three times each year, in September, February, and May. The first meeting was in September 1996.

meetings over 6 years, average attendance was 16 (range, 11-26). In addition, an average of 14 family members and friends (range, 5-23) have also attended each meeting. Seventy former patients have attended at least one meeting; 10 have attended 10 or more meetings. This represents $41 \%$ of the 170 patients who achieved remission from their acute episode of TTPHUS and were alive in 1996, when the meetings began. Meeting attendance was related to place of residence: 48 of 100 (48\%) former patients who live in the Oklahoma City metropolitan area have attended; 22 of $70(32 \%)$ who live outside the Oklahoma City metropolitan area have attended $(P=0.031)$.

Table I describes the characteristics of the 70 patients who have attended at least one meeting, compared to 100 patients who have not attended. Significantly more women attended, which could relate to a greater sense of comfort that women may have in discussion groups. Patient attendance was statistically different across the different clinical categories of patients at presentation $(P<0.001$, Table I). Patients whose episode of TTP-HUS occurred in association with pregnancy, who had acute, immunemediated drug-associated TTP-HUS (due to quinine or ticlopidine), whose episode was preceded by a prodrome of bloody diarrhea, or who had idiopathic TTP-HUS had higher attendance rates (45-73\%) than patients whose episode had followed bone marrow transplantation, who had dose-dependent drug-associated TTP-HUS (due to chemotherapy for advanced cancer or immunosuppression for organ transplantation), or who had an additional or alternative diagnosis (0-22\%). Patients who have had a relapse of their TTP-HUS were more likely to attend, probably because of greater concern for future recurrences.

Although some meetings have had structured programs, most are devoted to unstructured discussion and questions from the former patients and their families. Most questions are related to unfamiliarity with TTP-HUS: "What is TTP?" "What is HUS?"
"What exactly did I have?" "How can I describe my illness to my family and friends?" "Why were my problems different from hers?" "What causes it?" "Will it come back?" And many others. Even former patients whose acute episode was several years ago and who have attended multiple meetings appear to benefit from continuing discussion and improved familiarity with the serious illness they had. At the suggestion of many of our former patients who could not attend these meetings, and former patients from other locations who learned about the meetings from our Web site (http://moon.ouhsc.edu/jgeorge), a videotape was made of the May 2001 meeting; this is now distributed to current patients and sent to others who request it.

Questionnaires were sent to all currently surviving former patients in July 2002: 24 of 48 (50\%) former patients who had attended more than one meeting responded; 11 of $22(50 \%)$ who had attended one meeting responded; and even 21 of $59(36 \%)$ who had not attended a meeting responded. The 35 responses from patients who had attended at least one meeting also included 26 completed questionnaires from family and friends. Results for two of the questions are presented in Table II, demonstrating that the principal motivations for attending meetings were to talk with other former patients and to learn more about TTP-HUS. Additional comments that were added to the responses to the two questions presented in Table II provided insight into the benefit of these meetings. Several examples were: "It helps to know you're not alone." "It is very helpful to talk to others." "For me, personally, I don't need the group to be a 'support group' but more of a study group to disseminate information." In response to the question, "Is there anything we could change or add to make the meetings more helpful?", one response was, "Just don't stop. The meetings are very important."

When former patients who had not attended a meeting were asked, "Why have you have never at- 
TABLE I. Comparison of Patients Who Have Attended The Oklahoma TTP-HUS Study Group With Patients Who Have Not Attended*

\begin{tabular}{|c|c|c|c|}
\hline Variable & $\begin{array}{l}\text { Patients attended } \\
1 \text { or more meetings } \\
(\mathrm{n}=70)\end{array}$ & $\begin{array}{l}\text { Patients who have not } \\
\text { attended a meeting } \\
(\mathrm{n}=100)\end{array}$ & $P$ \\
\hline Age (years) & 45 & 43 & 0.467 \\
\hline Sex $(\%$ female $)$ & $84 \%$ & $68 \%$ & 0.016 \\
\hline Relapse & $23 \%$ & $8 \%$ & 0.006 \\
\hline Clinical category at presentation & & & $<0.001$ \\
\hline Bone marrow transplantation $(\mathrm{n}=4)$ & 0 & 4 & \\
\hline Pregnancy/postpartum $(\mathrm{n}=22)$ & 11 & 11 & \\
\hline \multicolumn{4}{|l|}{ Drug-association } \\
\hline Immune-mediated $(\mathrm{n}=15)$ & 10 & 5 & \\
\hline Dose-dependent $(\mathrm{n}=9)$ & 2 & 7 & \\
\hline Bloody diarrhea prodrome $(\mathrm{n}=11)$ & 8 & 3 & \\
\hline Additional/alternative diagnosis $(\mathrm{n}=29)$ & 3 & 26 & \\
\hline Idiopathic $(\mathrm{n}=80)$ & 36 & 44 & \\
\hline
\end{tabular}

*Patients who have attended one or more meetings are compared to patients who have not attended. It was assumed that all patients who had survived >30 days after completion of plasma exchange treatments and were alive in 1996, when the meetings began, could have attended. Clinical categories of patients have been previously defined [2]. Between the two attendance categories, age was compared using a $t$-test; sex and relapse were compared using a chi-square test. To determine if attendance rates for all 7 clinical categories were the same or different, a Fisher's exact test was used.

TABLE II. Results of a Questionnaire to Determine the Goals and Value Goals of The Oklahoma TTP-HUS Study Group*

\begin{tabular}{lrr}
\hline & & Responses \\
\cline { 2 - 3 } Questions & Former patients [n $=35]$ & Family, friends [n $=26]$ \\
\hline 1. "What was the most beneficial part of the meeting for you?" & & $18(69 \%)$ \\
$\quad$ Learning more about TTP-HUS & $21(60 \%)$ & $16(62 \%)$ \\
$\quad$ Talking to other people who have had TTP-HUS & $24(69 \%)$ & $16(62 \%)$ \\
$\quad$ Talking to Dr. George & $16(46 \%)$ & $17(65 \%)$ \\
2. "Was the meeting what you expected?" & $19(54 \%)$ & $8(32 \%)$ \\
$\quad$ Better than I expected & $14(41 \%)$ & 0 \\
What I expected & 0 & 0 \\
$\quad$ Not what I expected & & \\
\hline
\end{tabular}

*Questionnaires were mailed to former patients in the Oklahoma TTP-HUS Registry and their family and friends. Thirty-five of 70 $(50 \%)$ former patients responded (combining the responses from patients who had attended one meeting with response from patients who had attended more than one meeting); 26 of these responses also included responses from family members or friends. Two of the questions, which were identical on all three of these questionnaires, are reproduced. Former patients and their families and friends could check more than one response for question 1. Two former patients and one family member did not answer question 2.

tended these meetings?", distance and transportation difficulties were the primary reasons (15 of the 20 responses). Some patients now live outside of Oklahoma, and some Oklahoma residents live more than 100 miles from Oklahoma City. Another response to this question was, "We prefer not to think about it. It's just too painful."

In addition to providing benefit for former patients and their families, these meetings have also facilitated the research objectives of The Oklahoma TTP-HUS Registry. Continuous follow-up to document longterm outcomes, such as frequency of relapse, is a major research objective. This is aided not only by meeting attendance but also by the correspondence three times each year announcing the meetings. This regular correspondence maintains a continuous bond and supplements our twice-yearly telephone contacts with both former patients and their physicians. Also, discussions at the group meetings have consistently identified persistent cognitive difficulties and limited endurance, which have continued in spite of normal physical and laboratory examinations. Because of these descriptions, which have not previously been documented or reported, The Oklahoma TTP-HUS Registry initiated a study of health-related quality-oflife with the commonly used instrument, the SF-36, in 1998 [3].

Thirty-two of the 96 (34\%) AABB and ABC blood centers responded to our survey; none were aware of any organized program for patients who had recovered from TTP-HUS. One center, the Baltimore Rh Typing Laboratory, had a support group for patients who had recovered from TTP in the Baltimore/ Washington, DC, area with about 2-3 meetings per year from 1994-1997. These meetings stopped because of lack of staff and physician support, although this organization recognizes a continuing patient need and, therefore, a telephone response network is 
maintained (Caroline T. Shepherd, personal communication, July 2002). A support group, The TTP Network, was begun in England by a former patient in 1998. The TTP Network has a Web site (www.ttpnetwork.org.uk) with a monthly chat room.

In contrast to the lack of organized groups for support of patients who have recovered from TTPHUS, the Oklahoma City metropolitan area (population 1,083,346) currently has 274 support groups and wellness/education classes. Common categories are cancer (39 groups), grief (37 groups), prenatal/ parenting (27 groups), diabetes (16 groups), and mood disorders (14 groups). Some other support groups are for rare disorders, such as amyotrophic lateral sclerosis and mastocytosis.

\section{DISCUSSION}

The experience of The Oklahoma TTP-HUS Study Group suggests that it serves a previously unmet need. The most apparent value of these programs is to make a previously unfamiliar disorder more familiar. None of our patients had heard of TTP or HUS before their own diagnosis; most all of their primary physicians had also been unfamiliar with TTP-HUS, increasing apprehension among the patients and their families. Meetings have provided comfort and reassurance to former patients, their families and friends, diminishing the sense of isolation that is inevitable from their experience with an acute, potentially fatal illness that they cannot easily describe and discuss. Our initial concern, that the diversity of presenting features and critical complications would increase apprehension, was unwarranted. The former patients who have attended these meetings are not disturbed by alarming descriptions or even by discussion of death from TTP-HUS.

Beyond this apparent benefit for former patients and their families and friends, these meetings have been a valuable asset for maintaining patient follow- up. The most important gap in our understanding of the clinical course and consequences of TTP-HUS is the lack of complete long-term follow-up in reported case series. The Oklahoma TTP-HUS Registry currently has complete follow-up on 279 of 280 patients. Letters to announce these meetings are mailed to all surviving patients three times each year, which assures that our contact information is up-to-date. The opportunity for the staff of The Oklahoma TTP-HUS Registry to meet former patients, to discuss their problems, and to describe the importance of long-term follow-up enhances the importance of our efforts.

An unexpected benefit of these meetings has been better understanding of long-term outcomes following recovery from an acute episode of TTP-HUS. Most former patients describe persistent problems with cognitive ability and endurance. These concerns led to the incorporation of regular quality-of-life assessments during our follow-up evaluations of all patients. These have demonstrated that our former patients, as a group, have significantly impaired health-related quality-of-life compared to the United States population [3].

The experience of The Oklahoma TTP-HUS Study Group suggests that there may be a need for programs of continuing support for patients who have recovered from TTP-HUS. Our experience also suggests that there is more to learn from these former patients.

\section{REFERENCES}

1. George JN. How I treat patients with thrombotic thrombocytopenic purpura-hemolytic uremic syndrome. Blood 2000; 96:1223-1229.

2. George JN, Vesely SK. Thrombotic thrombocytopenic purpura-hemolytic uremic syndrome: diagnosis and management. Cleveland Clin J Med 2001;68:857-878.

3. Howard MA, Perdue JJ, Christopher A, Terrell DR, Lammle B, Vesely SK, et al. Long-term effects of thrombotic thrombocytopenic purpura on health-related quality-of-life (abstract). Blood 2002;100:870a. 